\title{
Brucellosis in Camels and its Public Health Significance for Humans
}

\author{
Neharika Saxena* and Rajni Joshi \\ Department of Veterinary Public Health, College of Veterinary and Animal Science, \\ Rajasthan University of Veterinary and Animal Sciences, Bikaner-334001, India \\ *Corresponding author
}

\section{Keywords}

Malta fever, Mediterranean fever, undulant fever and gastric remittent fever

\section{Article Info}

Accepted:

12 March 2021

Available Online:

10 April 2021

\section{Introduction}

Brucellosis is a zoonotic disease that affects all domestic animals including camels. It can infect humans also. Brucellosis in humans is known by various names including Malta fever, Mediterranean fever, undulant fever and gastric remittent fever. Brucellosis is spread across the Mediterranean region of Europe, the Middle East, North and East Africa, Central and South Asia, and Central and South America (Corbel, 2006). It is transmitted to people by coming in contact with animals that are infected or their contaminated products.

Brucellosis is caused by bacteria of the Brucella group. Brucella are facultative intracellular coccobacilli that have a predilection towards placental trophoblasts and for the rough endoplasmic reticulum (Ramirez-Romero, 1998). There are many modes for Brucella through which it can gain entry into the body. For example, the digestive tract, intact skin, mucous membranes and via lungs. It displays a predilection towards reticulo-endothelial tissues like spleen, liver and blood vascular system once inside the blood (Greenfield et al., 2002). Animals that are mostly infected by this bacterium include cattle, goats, sheep, dogs, pigs and camels among others. Humans act as accidental host to this disease while animals are its natural reservoirs (CDC, 2019).

There are six main types of Brucella. They are B. suis, B. abortus, B. melitensis, B. ovis, B. 
neotomae, and B. canis (WHO, 2006). Some of these are pathogenic to man as well. They are B. canis, B. abortus, B. suis, and B. melitensis in the ascending order of pathogenicity (Corbel, 2006). Different species of Brucella infect different animals, camels are infected by Brucella melitensis and Brucella abortus (OIE, 2009). In recent times, it has emerged as a problem of serious public health concern worldwide (Radostits et al., 2007).

Brucellosis has also been listed as an occupational disease. The people at risk includes Veterinarians, animal handlers, employees of meat-packing plants, slaughter house workers and lab workers (CDC, 2015). In man, this disease manifests various symptoms like undulating fever, profuse sweating, headache, anorexia, joint pain and spondylitis (Pandit et al., 2013). In animals, it leads to abortion, stillbirth, epididymitis, orchitis and placentitis (OIE, 2009). Infection is transmitted to humans from infected animals mainly by direct or indirect contact with animals, and consumption of unpasteurized milk, contaminated meat and milk products.

\section{Economic importance of camel}

Old world camels are ungulates of the genus Camelus, which can be differentiated into two species: the two-humped Bactrian camels (Camelus bactrianus) and the one-humped, Dromedarian, Arabic camels (Camelus dromedarius) (Schwartz and Dioli, 1992). In many developing countries of Asia and Africa, camel is one of the main sources of income for nomadic population (Abbas and Agab, 2002). Both species are held not only as working animals, but also as providers of milk, meat, wool, calfskin and fuel. The latter is the main source of income in Eastern and Central Asia, whereas others are found in desert areas of West, North Africa and Near and Middle East
(Wilson and Reeder, 2005). Camels are, in addition, a good source of low-cost food, since they make reasonably heavy carcasses in inexpensive livestock systems (Kadim et al., 2008). Camel meat is predominantly eaten in countries surrounding the Red Sea. It is a key component in the diet of many nomadic societies. The market is growing and the commercialization and use of camel milk is on rising (Aklilu and Catley, 2011).

In Central Asia, the Near and Middle East, Northern Africa and Sub-Saharan Africa, camels have an important socioeconomic role in dry and semi-dry zones (Abbas and Agab 2002; Sprague et al., 2012). Camels represent important providers of meat, clothing, coal, wool and milk in many Asian and African countries. The consumption of milk from camels has been growing progressively due to its wealthy composition in minerals (Potassium, Sodium, Copper, Iron and Zinc) and Ascorbic acid additionally because of its low steroid and alcohol content when put next to ruminant milk (Farah, 1993; Khaskheli et al., 2005). Underneath dry climates, camels are among the foremost necessary animals raised within the country. During the arid and dry season, they are a major source of milk, and may withstand drought for a long time (Wakene and Mamo, 2017).

In the arid areas of Asia and Africa there are many developing countries where camel holds a key position as a livestock for nomadic and rural populations. Camel is reared for its milk and meat. It is also used for transportation purposes (Gwida et al., 2012). Recently, camel milk has become widely commercialized with the availability of a wider market (Verma et al., 2018). An important factor for this has been the increase in consumption of camel milk which can be credited to its varied health benefits (Zibaee et $a l ., 2015)$. Camel milk is used in the treatment of Diabetes mellitus (Mirmiran et al., 2017). 
The FAO estimated the gross production value of camel milk to be US\$ 342 million and of meat to be US\$1000 million in 2009 (FAO, 2011). Camels are mostly reared by nomads in Africa and Asia for meat, fiber (hair and wool), milk and transport and its dung is used for fuel. FAO has estimated the population of camels to be 35 million worldwide. About $5 \%$ of the total milk produced in sub-Saharan regions of Africa is contributed by camels. Camel dairy products in arid and semi-arid areas have given the nomadic livestock herders a rich source of income along with a source of food (FAO, 2019). The camel plays a role which is vital for the survival and socioeconomic development of the dry and arid regions of Asia and Africa.

In India, in the arid regions of Gujarat and Rajasthan, the livelihood of people depends on camels, especially the camel breeding Raika community. Camel milk which is mostly consumed by nomads and herdsmen with their families is a by-product of breeding camels. Camel meat consumption in India is limited to a few Muslim communities that sacrifice camels on festive occasions only (LPPS, 2005).

\section{Brucellosis in camels}

Brucellosis remains endemic (Boral et al., 2009) all over the world with a few exceptions of countries which have eradicated the disease (Basappa and Amarnath, 2008). With the emergence or re-emergence of new foci, there has been a continuous change in the worldwide spread of Brucellosis (Boral et al., 2009). Brucellosis is still endemic in India (Renukaradhya et al., 2002). Camel Brucellosis is a significant but neglected disease in India.

Camels are very susceptible to infection with Brucella melitensis and Brucella abortus, which are pathogenic to man (Omar et al.,
2010). Brucellosis is insidious in camels as it is mostly asymptomatic. Furthermore, its diagnostic tests have not been properly validated for camels causing aberrations in accurate diagnosis of this disease (Musa et al., 2001). The clinical manifestations of Brucellosis may vary from abortion to asymptomatic in camels (Musa et al., 2008). Symptoms in dams are hydrobursitis, granulomatous endometritis and adhesions in ovario-bursal region. Retention of placenta and delay in sexual maturity along with infertility have been reported (Musa et al., 2001). In males, orchitis has been reported (Abbas \& Agab, 2002). Acute lameness along with hygroma and arthritis has been reported (Musa et al., 2008). The different species of Brucella that cause infection in camels are $B$. melitensis and B. abortus. The Biotype 3 of Brucella melitensis is the most prevalent.

Brucellosis has been found to be present in Camelus dromedarius, which is the onehumped camel (Adamu et al., 2014) and in Camelus bactrianus, the camel with two humps (Bayasgalan, 2018). Indirect or direct contact with camels may lead to Brucellosis in humans (Ramet, 2001). Camel Brucellosis on the animal - human interface is an emerging problem from public health point of view.

Camel Brucellosis was first documented in 1931 (Abbas and Agab, 2002). For Brucella spp, camel is primarily considered secondary host as they're tainted with $B$. abortus or $B$. melitensis field strains which also affect cattle and small ruminants like sheep and goat (Dawood, 2008; Gwida et al., 2012), respectively.

Contaminated camel herds are mostly detected by serological tests in the most active camelkeeping countries. The factors predisposing camel to Brucellosis are not clearly understood. It is difficult to estimate the incidence of Brucellosis in camels, since they 
reveal very few clinical signs. (Khadjeh et al., 1999; Dawood, 2008; Musa et al., 2008) and camel Brucellosis still remains an insidious and neglected disease which is present in all countries where camels are reared such as Russia, Mongolia, Azerbaijan, Egypt, Sudan, Jordan, Saudi Arabia, Kuwait, Libya, and Iran (Khadjeh et al., 1999; Zowghi et al., 2008; Sprague et al., 2012; Golshani and Buozari, 2017; Neha et al., 2017).

A multitude of risk factors have been described for Brucellosis in camels, which include contact with small and large ruminants and traditional livestock breeding practices (Abbas and Agab, 2002). The growing economic and livelihood value of camelderived products in many arid and semi-arid regions worldwide has led to the rapid spread of camel herds with close contact with cattle and small ruminants in pastures. Both activities tended to dramatically increase the risks of camel Brucellosis infections. Hadush et al., (2013) reported that close contact with other livestock increased the risk of camel Brucellosis up to 3.6 times. All these problems are clearly cascading consequences of human activity and could be viewed as risk factors for anthropogeny. Clinical symptoms are uncommon, and may include loss of reproduction in camels after miscarriages or infections with B. melitensis (Al-Majali et al., 2008; Dawood, 2008).

Brucellosis is reported from all the countries that rear camels for their milk and meat (Gwida et al., 2012). The occurrence of this disease in camels is closely related to husbandry and breeding practices (Omer et al., 2010). in a study conducted in Jorbeer village of Rajasthan in India prevalence of camel Brucellosis was found to be $3.8 \%$. Among the 210 samples collected from adjoining villages, $5.23 \%$ were seropositive (Mathur and Bhargava, 1979). In a study conducted during 2008-2012 in Rajasthan state of India, 78 serum samples from camels (females, $n=73$ and males, $\mathrm{n}=5$ ) with an abortive history were collected for Brucellosis investigations. All the camels were mature and single humped, reared semi-intensively. A prevalence of $4.9 \%$ and $8.9 \%$ by ELISA and RBPT, respectively was reported among the 78 camels tested. Out of 42 camels tested by PCR, DNA from one female camel amplified $223 \mathrm{bp}$ product which is Brucella specific (Shome et al., 2013).

Brucellosis was found to be endemic in camels in the arid regions of Gujarat with a prevalence of $11.64 \%$ and $4.54 \%$ out of 352 serum samples tested by RBPT and i-ELISA, respectively. A total of 52 milk samples were also tested by milk ring test out of which 8 $(15.38 \%)$ samples were found positive. In this study, females were found to have a higher prevalence of Brucellosis than males (Chauhan et al., 2017).

Although there have been few studies on camel Brucellosis in India, there are several reports of this disease around the world. In a sero-epidemiological research conducted in Punjab region of Pakistan, the prevalence of Brucellosis in camels was reported to be 2.0 $3.07 \%$ (Gul et al., 2014). In another study conducted in Punjab province of Pakistan, 761 camels were tested for Brucellosis by RBPT and C-ELISA. The prevalence was found to be $3.41 \%$ by RBPT and 18 samples were positive by C-ELISA (Shahzad et al., 2017).

In a study conducted in Egypt, the seroprevalence of Brucellosis was found to be $3.73 \%$ and $4.17 \%$ by competitive ELISA (CELISA) and modified RBPT (m RBPT), respectively (Hosein et al., 2016). Evidence for serological incidence of Brucellosis has been reported from Saudi Arabia and Jordan (Alshaikh et al., 2007; Dawood, 2008). In a study conducted in Jordan, the seroprevalence of Brucella positive camels in Jordan was 
found to be $12.1 \%$. This study also entailed the isolation of Brucella melitensis biotype 3 from aborted fetuses of camel (Al-Majali et al., 2008).

In a study conducted on the two-humped Bactrian camels from the arid region of Mongolia, China the overall prevalence was $2.3 \%$ for Brucellosis. B. abortus was isolated from both camels and cattle tested under this study. Association with Brucella infected cattle was elucidated as the reason for seropositivity of camels (Bayasgalan et al., 2018).

In an extensive study conducted on 2,630 adult camels from Central Saudi Arabia, sera were tested by RBPT and BPAT (Brucella plate agglutination test). The total prevalence of this disease was found to be $8 \%$. The infection in camels was attributed to close contact with ruminants leading to $B$. melitensis infection (Radwan et al., 1992).

Many countries of Africa have also reported evidence for endemicity of Brucellosis in camel population. In the arid Afar region of Nigeria, the camel population infected by Brucellosis was found to have overall prevalence of $7.6 \%$ and $11.9 \%$ by Complement Fixation Test and RBPT out of 768 camels screened by CFT and RBPT, respectively (Zewolda and Wereta, 2012). Brucellosis is prevalent in camels of East Africa at a rate of $1.9-40.5 \%$ (Wakene and Mamo, 2017). Thus camel Brucellosis is prevalent in almost all camel rearing countries of the world with an exception of Australia (Gwida et al., 2012). In India, it lies in a neglected state with very few studies conducted on camels.

Brucellosis in camelids caused by $B$. melitensis and B. abortus has been reported in all camel rearing countries except for Australia and the event in Saudi Arabia seems closely linked to animal handling and breeding activities (Richard, 1980) which Omer et al., (2010) were able to prove well in their study. The Brucellosis seropositivity of a female dromedary herd which was in close contact with small ruminants $(n=165)$ was compared to that of a closed female dromedary herd $(\mathrm{n}=$ 95) using the RBT, SAT and cELISA. The prevalence of Brucellosis in the open herd was $8.5 \%$, compared to $1 \%$ in the closed herd.

High prevalence among animals and in herd have been reported from different countries, which pose a severe risk to humans and other livestock. The infection rate in some regions of the former Soviet Union where Bactrian camels are kept on large farms, is $15 \%$ (Palgov \& Zhulobovski, 1964), whereas in countries such as Chad or Ethiopia having more extensive forms of camel husbandry, the seroprevalence of Brucellosis is 3.8\% (Graber, 1968) and 5.5\% (Richard, 1980), respectively. Radwan et al., (1992) and Ghoneim and Amjad (1993) reported similar variations in seroprevalence in Saudi Arabia. In intensively farmed camels, they recorded a high incidence of camel Brucellosis than those in the freegrazing desert camels. In Sudan, the prevalence differs according to camel husbandry system: agropastoralists reported a higher Brucellosis prevalence (31.5 per cent) than nomads (21.4 per cent) (Agab, 1993; Agab, 1998; Abbas and Agab, 2002).

\section{Brucellosis in human beings: zoonotic aspect}

Brucellosis can be readily transmitted from camels to humans by milk or its products. A high number of cases of human Brucellosis have been reported in various parts of the world due to consumption of camel milk and meat arousing a serious public health concern (Dawood, 2008). Camels are a secondary host for Brucella spp. They are extremely vulnerable to Brucella abortus and Brucella 
melitensis infections (Musa et al., 2008). High prevalence of Brucellosis in camels poses a continuous risk of infection in humans, primarily through intake of unpasteurized camel milk and other unpasteurized dairy products (Sprague et al., 2012).

Brucellosis is a zoonosis known by various names in humans like Mediterranean fever, Undulant fever and Malta fever. The growing urbanization along with booming animal industries combined with the absence of hygiene in animal husbandry and food industry account for the increase in risk for spread of Brucellosis. The transmission of Brucellosis in humans is mainly through intake of dairy products and raw milk. Intake of unpasteurized milk from camels and small ruminants along with cheese and curd are important risk factors (Godfroid et al., 2005; WHO, 2006). It is also transmitted via ingestion of uncooked meat, direct contact with animals that are infected and through aerosols of infectious materials. It is also an occupational hazard to those who are exposed to infected animals like the Veterinarians and laboratory workers (WHO, 2006). It often leads to spread of infection by aerosols. It can also be transmitted sexually or by blood transfusion (Sathyanarayan et al., 2011).

Brucellosis is among the most widespread infectious diseases globally as per the Food and Agriculture Organization (FAO) of the United Nations, the World Health Organization (WHO) and Office International des Epizooties (OIE) (Schelling et al., 2003). According to the OIE, it is the second most important zoonotic disease, infecting 500,000 humans every year (Pappas et al., 2006).

In humans, Brucellosis manifests as an acute febrile illness and intermittent fever. It is often followed by anorexia, malaise and prostration along with enlargement of spleen, lymph nodes and liver. In most of the cases it manifests as an acute disease. The clinical symptoms manifest as fever, night sweats, arthralgia and spondylitis. If untreated, the fever becomes undulant in nature, hence giving it the name "Undulant fever" (WHO, 2006). In rural areas, Brucellosis is very common as the farmers often come in direct or indirect contact with the livestock and drink raw milk. The distribution of contaminated milk in urban areas may also lead to the spread of the disease (Mantur and Amarnath, 2008; Amenu et al., 2010).

In a study conducted in the western Rajasthan, about 350 susceptible people (Veterinarians, slaughter house workers and milk vendors) were tested with SFA (Stained Febrile Antigen) test and ELISA (Enzyme linked immunosorbent assay) and their clinical history was recorded. It was found that $42 \%$ of meat handlers, $28 \%$ of veterinarians and milkmen with $13 \%$ of Pyrexia of Unknown Origin (PUO) cases and $4 \%$ of normal healthy people tested positive for Brucellosis. It pointed to the fact that people in animal contact are much more at risk of contacting Brucellosis than their counterparts who were not in contact. A positive co-relation was observed between rearing of camels and consumption of raw milk with a raised Brucella antibody titre (Ali et al., 2014).

In a research conducted in Bikaner (Northwest India), a total of 175 people were tested for Brucellosis of which 155 were from villages. Of the infected, two were veterinarians. Amongst the risk factors elucidated, the history of ingestion of raw milk ranked the highest $(86.86 \%)$ with animal contact whether occupational $(62.28 \%)$ or household $(16 \%)$ ranking behind (Kochar et al., 2007). In Kanvari village located in Churu district of Rajasthan, there was an outbreak of polyarthritis among 48 people, which turned out to be Brucellosis. Among these, 91.6\% of the people were diagnosed positive (Kalla et 
al., 2001). Mathur (1964) reported 8.5 per cent of the employees of an organized dairy farm at Karnal having Brucella agglutinin in a titre of $80 \mathrm{IU}$ and above. Phadke and Phadke (1974) at Pune tested 611 serum samples received for VDRL test and 46 serum samples for Widal test, for the presence of Brucella agglutinins. Out of the 611 serum samples received for VDRL test and 46 serum samples received for Widal test, Brucella agglutinins were detected in $21.8 \%$ and $3.1 \%$ samples, respectively.

In a study conducted by Kadri et al., (2000), sera from a total of 3,532 patients with pyrexia of unknown origin were analyzed for Brucellosis employing tube agglutination test. Samples found to be positive for Brucellosis were $0.8 \%$ of the total sera. Seropositive male to female ratio was $3: 1$.

Thakur and Thapliyal (2002) conducted a study in Uttaranchal where a total of 352 human serum samples were screened for Brucellosis. They found a prevalence rate of 4.97 per cent in samples that included specimens from persons occupationally exposed to animals in Uttaranchal. Kumar and Nanu (2005) from Kerala reported that seropositivity for Brucellosis was 1.6 per cent. Among the general population, a prevalence of 2.45 per cent was observed and among the veterinary students, it was 1.14 per cent. Prevalence among field veterinarians was 17.39 per cent.

Agashthy et al., (2007) in their study on Brucellosis in 618 high risk group individuals found that the disease prevalence was at 41.23 per cent in veterinary inspectors, 30.92 per cent in veterinary assistants, 12.37 per cent in veterinary officers, 6.18 per cent in veterinary supervisors, 6.18 per cent in group D workers, 2.06 per cent in shepherds and 1.03 per cent in butchers, respectively. In a study carried out in Ethiopia, the risk of transmission of Brucellosis was found to be $88.33 \%$ in camel owners that are in direct contact with their camels. In this study, 120 camel owners were interviewed by the questionnaire method. Of these, $109(91 \%)$ consumed raw milk on a regular basis and $12(11 \%)$ of them had Brucella positive camels. About $91 \%$ of the 120 camel owners interviewed, drank fresh raw milk regularly, and $11.01 \%$ of them owned camels that were Brucella positive (Habtamu et al., 2015).

In a questionnaire survey conducted on camel owners in Somalia, $100 \%$ of the owners confirmed the intake of raw camel milk and $63 \%$ reported bare handling of aborted fetuses. Lack of awareness of this disease among camel owners was found among $77 \%$ of the total respondents (Kadle et al., 2017).

In an outbreak reported from Qatar, Brucellosis was diagnosed in 14 people from a family residing in a rural area of Qatar region. Males had predominance in this disease (92.9\%) with the median age of about 10 years. Brucella melitensis and Brucella abortus were isolated and identified using serological tests and blood culture. Consumption of contaminated milk from an infected camel was identified as the source of the outbreak (Garcell et al., 2016).

A serological investigation was conducted on 15 members of a camel rearing Bedouin extended family of southern Israel. All were detected with acute Brucellosis, manifesting undulant fever and arthralgia. Brucella melitensis was isolated from $50 \%$ of the infected population with SAT (serum agglutination test) titres ranging from 1:160 or higher in $60 \%$ of cases. The source of this outbreak was attributed to a female camel that had tested positive for Brucellosis by serological tests (Shimol et al., 2012).

In Germany, a curious case of a young pregnant Syrian refugee was reported who was 
diagnosed with Brucella infection right after her delivery. Brucella melitensis was confirmed by real-time PCR and MALDITOF mass spectrometry. The risk was attributed to consumption of camel milk (Grunow et al., 2016).

In a study conducted in Qatar on patients admitted in a hospital, 41 were diagnosed with Brucellosis. Most of the patients had earlier ingested raw milk and had been in contact with camels. Clinical symptoms manifested were prolonged fever $(85.7 \%)$, arthralgia and muscle pain. Co-infection with Brucella abortus and Brucella melitensis was shown by serology and positive blood culture in 37 of the tested patients. $14.6 \%$ of the people were found to be serologically positive and $12.2 \%$ were found positive by blood culture (Garcell et al., 2018).

In a cross sectional study conducted in Oromia Regional State of Ethiopia, the seroprevalence of Brucellosis in camels and humans was determined along with an assessment of the risk factors responsible for its transmission. A total of 250 humans and 768 camels were tested by Rose Bengal plate test (RBPT) and complement fixation test (CFT) along with a questionnaire survey. The prevalence in camels was found to be $36.5 \%$. Among humans, 15 people were found positive out of 250 persons tested. The risk of transmission of the disease was found to be the highest amongst those who handled retained membranes of fetus $(p=0.000)$ and lesser $(\mathrm{p}=0.000)$ in those who consumed raw milk (Mekonnen, 2016).

In a study conducted in Al-Qassim region of Saudi Arabia between 2010 and 2014, 4283 cases Brucellosis in humans were notified. Out of these, $46.5 \%$ were farmers and animal handlers. The most common clinical symptoms were joint pain $(72.7 \%)$, fever (79.7\%), and muscle pain $(70.9 \%)$. There was a history of consumption of unpasteurized milk in $55.6 \%$ of the cases and $80.7 \%$ of the people had been in direct or indirect contact with animals (Alsoghair, 2016).

\section{Diagnostic Tests for Brucellosis}

The classical serology tests conducted for the Brucella spp licensed for use only in livestock include CFT, Rose Bengal Test (RBT) and Serum Agglutination Test (SAT). The CFT is required by the World Health Organization for compulsory international trade inspection. All three tests are specific, i.e. they give correct identification of true positive animals and do not provide for single animals (Godfroid et al., 2002). Isolation of the causative agent has been reported from the lymph (Abu et al., 1989), aborted fetuses, vaginal swabbing (Gameel et al.,1993), milk (Radwan et al.,1992; Radwan et al.,1995), semen, and testes (Agab et al., 1996).

Gwida et al., (2011) compared multiple serological tests in a previous study, i.e. 895 sera from clinically sound camels, RBT, SAT, CFT, cELISA and the FPA test. FPA (79.3\%), followed by the CFT in descending order (71.4\%), RBT (70.7\%), SAT (70.6\%) and the cELISA $(68.8 \%)$ gave the best results for detecting the presence of anti-Brucella antibodies. In all serological studies, only $66.5 \%$ of samples were positive. In addition, the analysis tested the utility of a PCR in real time, which was observable in 84.8 per cent of samples positive for the Brucella cell surface gene, that codes for bcsp31 kDa protein.

Different diagnostic tests for Brucellosis are used in humans. In some studies, bone marrow (BM) culture is the current gold standard tool for verifying a Brucellosis case. The sensitivity of Brucella blood cultures was reported as 80 per cent - 90 per cent in the acute form of Brucellosis, although the sensitivity was reported as 30 per cent - 70 per 
cent (Espinosa et al., 2009) in the chronic type. Rose Bengal test is fast, but in its chronic form this test has many false-negative results (Roushan et al., 2005). The most popular and appropriate serological diagnostic test for human Brucellosis is the Serum Agglutination Test (SAT). It is more acceptable to use SAT titer of 1:320 and titer 2-mercoptoetanol (2ME) of 1:160 in endemic areas. The Coombs' test is useful for diagnosing relapsed cases. Lateral flow assay is used in endemic regions to overlook the patient and this test provides quick results (Roushan et al., 2005; Nimri, 2003). For the diagnosis of Brucella, molecular tests such as polymerase chain reaction (PCR) have generally spread several decades ago. Today, this test is mostly used to assess the efficacy of the treatment.

RBPT, ELISA and PCR are the most widely used tests for the laboratory diagnosis of Brucellosis in cattle, camel and humans (Alton, 1990). It is widely believed that serological tests used for B. abortus infection in cattle are also adequate for serodiagnosis of B. melitensis infection in camels and humans.

\section{Rose Bengal Plate Test (RBPT)}

Rose Bengal Plate Test (RBPT) or Rose Bengal Test (RBT) is internationally acknowledged as the test of choice for the screening of Brucellosis in camels and humans (Garin-Bastuji and Blasco, 2004).

However, standardization conditions suitable for diagnosing cattle infection (MacMillan, 1990; European Commission, 2002; GarinBastuji and Blasco, 2004) are not adequate in camels and humans (Blasco et al., 1994a, b) and account for the low sensitivity of RBT antigens in them (Blasco et al., 1994a; Falade, 1978, 1983) along with the fact that a high proportion of animals in infected areas give results negative in RBT, but positive in CFT, question the efficacy of the RBT as an individual test (Blasco et al., 1994a).

\section{Enzyme linked immunosorbent assay (ELISA)}

Good diagnostic results have been obtained in camels and humans with ELISA or, at a lesser degree, ELISA using various antigens, but generally those with a high content of smooth lipopolysaccharide (LPS) are the most reliable. These ELISAs provide similar or better sensitivity than both RBT and CFT, but like classical tests, ELISAs are unable to differentiate infected animals from animals recently vaccinated with the Rev-1 vaccine (Jimenez' de Bagu“es' et al., 1992; Blasco et al., 1994b; D'1az-Aparicio et al., 1994; Delgado et al., 1995; Ficapal et al., 1995; Marin et al., 1999; Ferreira et al., 2003) or animals infected with cross-reacting bacteria.

However, the association of the conjunctival vaccination procedure and the presence of a moderate interval after vaccination minimize or abrogate the specificity problems. A similar indirect technique has been also proposed for diagnosing Brucellosis in individual or pooled milk samples (Alonso-Urmeneta et al., 1998), but the test lacks sensitivity when compared with serological tests.

A highly immunogenic periplasmic protein from B. abortus (Rossetti et al., 1996) or $B$. melitensis (Cloeckaert et al., 1996a) has been applied to Brucellosis diagnosis in different host species. ELISA employing this antigen could be sensitive and specific for detecting $B$. melitensis infection in camels and humans. It is useful in differentiating Rev-1 vaccinated from infected animals (Debbarh et al., 1995, 1996b; Cloeckaert et al., 1996b). All these ELISAs have potential advantages in sensitivity and specificity with respect to both RBT and CFT, but their diagnostic efficacy at large scale is unknown and a great deal of 
standardization work is required (GarinBastuji and Blasco, 2004).

\section{Sensitivity and specificity of various diagnostic tests}

Different diagnostic tests have been validated for diagnosing Brucellosis in camels and humans, but only the Rose Bengal test (RBT) and the complement fixation test (CFT) are approved for diagnosis of camel and human Brucellosis in the European Union (EU) legislation on intra-community trade (Council Directive 91/68/EEC). However, there is evidence that both tests are less sensitive and specific for the diagnosis of Brucellosis in camels and humans than in cattle (Blasco et al., 1994; Garin-Bastuji et al., 1998).

According to Biancifiori et al., (2000), the ELISA has a diagnostic sensitivity (99.4\%) and specificity (98.9\%) in camels and humans comparable to that of many standard indirect ELISA methods. In addition, the test proved able to distinguish between vaccinated and infected animals with an accuracy of up to $90 \%$ and result reproducibility of $93 \%$. They concluded that ELISA could be useful for differentiation of Rev.1 vaccinated and naturally infected camels and humans.

The serological tests used in earlier studies were the Rose Bengal Test (RBT), Standard Tube Agglutination Test, ELISA or Plate Agglutination Test. None of the aforementioned tests are perfect. Moreover, the performance of these tests has not been validated in naturally infected camels and humans (Alton et al., 1988; OIE, 2008).

The TAT among all tests used in a study gave the highest rate of positive animals compared with other traditional serological tests. This was explained by the fact that the test has a high sensitivity in respect of $\operatorname{IgM}$ rather than IgG as reported by Alton (1977). On the other hand, MacMillan (1990) reported that TAT failed to show significant titres in recent and chronic Brucella infections. While Corbel (1972) reported that TAT gives false positive reaction as a result of cross reaction between the antigens of Brucella and other organisms or due to the presence of non specific agglutinins in bovine sera. The presence of some samples collected from non reactors (Brucella - free cows) reacted positively with RBPT, BAPT and TAT. This may be attributed to the presence of some bacteria as Escherichia coli, Salmonella Dublin, Yersinia enterocolitica 0:9 and Pasteurella tularensis in the body fluids and secretions which react positively with the tests used in diagnosis of Brucellosis causing faults or error in the interpretation of the results.

The FPA was reported to be the test with the smallest sensitivity and I-ELISA that with the smallest specificity. I-ELISA was found to be the most sensitive test, whilst cELISA the most specific. The best positive predictive value was of cELISA followed by the FPA. ELISA had the best negative predictive value, which is expected due to the use of monoclonal antibodies (Nielsen et al., 1989). I-ELISA would be valuable for use at the early stage of a control program, whilst ELISA at its final stage. The FPA was found to be easier, cheaper and quicker to perform; further investigation should be carried to establish its value in large scale surveys, where a great number of samples need to be tested. Furthermore, Nielsen et al., (2001) have reported its use in testing stored whole blood samples with an almost $100 \%$ sensitivity and specificity; this can be an added advantage. The test may also be used in samples from all animal species, as well as in poor quality samples (Nielsen et al., 2001).

Reddy et al., (2014) applied multiple tests like RBPT, I-ELISA and Dot-ELISA to determine the apparent prevalence of camel and human 
Brucellosis in Karnataka and compare the relative sensitivities and specificities among the different tests applied. Test-wise, the seroprevalence in camels and humans was $5.15 \%$ by RBPT, $6.34 \%$ by STAT, $1.98 \%$ by 2-MET, $9.52 \%$ by I-ELISA and $7.14 \%$ by Dot-ELISA, respectively. The prevalence of Brucellosis was found to be highest among camels and humans of northeast Karnataka followed by northwest Karnataka, central Karnataka and south Karnataka. I-ELISA detected maximum number of positive samples. Considering I-ELISA as the reference, the relative sensitivity values of different tests are in the following order: DotELISA $>$ STAT $>$ RBPT.

Brucellosis in camels is endemic in certain countries including India. Humans in contact with Brucellosis affected camels or their products like milk, meat, skin etc. can get the infection. Thus, camel Brucellosis poses a serious public health hazard to the camel owners, attendants, veterinarians and slaughter house workers etc. More attention is needed to control this neglected yet important zoonosis owing to its affect on humans.

\section{Conflict of interest}

The Authors declare that there is no conflict of interest.

\section{References}

Abbas, B. and Agab, H. 2002. A review of camel brucellosis. Preventive Veterinary Medicine 55: 47-56.

Abu Damir, H., Tag El Din, M. H., Kenyon, S. J. and Idris, O. F. 1989. Isolation of Brucella abortus from experimentally infected dromedary camels in Sudan: a preliminary report. Veterinary Research Communications 13: 403406.

Adamu, S., Tijjani, A., Adamu, N., Atsanda,
N., Ali, S., Gashua, M. and Simon, F. 2014. Sero-prevalence of Brucellosis in One-Humped Camel (Camelus dromedarius) Herds In Yobe State, Nigeria. International Journal of Livestock Research, 4(4): 36-42.

Agab, H., Abbas, B., Ahmed, H. J. and Mamoun, I. E. 1996. First report on the isolation of Brucella abortus biovar 3 from camel (Camelus dromedarius) in the Sudan. Revue d'elevage et de medecine veterinaire des pays tropicaux 47: 361-3.

Agab, H. R. D. 1993. Epidemiology of camel diseases in Eastern Sudan with emphasis on brucellosis. M.V.Sc. Thesis. University of Khartoum, Sudan.

Agab, H.R.D. 1998. Camel pastoralism in the Butana region of eastern Sudan: common diseases with emphasis on brucellosis. J. Camel Pract. Res., 5 (1): 131-136.

Agashthy, A. S., Isloor, S. and Prabhudas, K. 2007. brucellosis in high risk group individuals. Ind. J Med. Microbl. 25(1): 20-31.

Akililu, Y. and Catley, A. 2011. Shifting Sands: the commercialization of camels in mid altitude Ethiopia and beyond. Addis Ababa: Feinstein International Center, Tufts University p1-42.

Ali, S., Bohra, G. K., Kothari, D., Kumar, D. and Vyas, T. 2014. Seroprevalence of Brucellosis in western Rajasthan. JMSCR 2(1): 332.

Al-Majali, A. M., Al-Qudah, K. M., AlTarazi, Y. H. and A 1 Rawashdeh, O.F. 2008. Risk factors associated with camel brucellosis in Jordan. Trop. Anim. Health Prod., 40: 193-200.

Alonso-Urmeneta, B., Marin, C. M., Aragon, V., Blasco, J. M., Diaz, R. and Moriyon, I. 1998. Evaluation of lipopolysaccharides and 
polysaccharides of different epitopic structures in the enzyme-linked immunosorbent assay for diagnosis of Brucellosis in small ruminants and cattle. Clinical Diagnostic and Laboratory Immunology 5: 749-754.

Alshaikh, M. A., Aljumaah, R., Alhaidary, A. A., and Korashi, M. A. 2007. Camel brucellosis in Riyadh Region, Saudi Arabia. Journal of Camel Practice and Research, 14(2): 113-117.

Alsoghair, M. I. 2016. Epidemiological characteristics of human brucellosis in Al-Qassim region, Saudi Arabia, between 2010 and 2014. Int J Community Med Public Health. 3(2): $397-402$.

Alton, G. G. 1977. Report to the Government of the United Arab Republic on the control of Brucellosis. FAO Report No. 1633, FAO, Rome.

Alton, G.G. 1990. Brucella melitensis. In: Nielsen, K. and Duncan, J. R. (eds.) Animal Brucellosis. CRC Press Inc., Boca Raton, Florida pp 383-409.

Alton, G. G., Jones, L. M., Angus, R. D. and Verger, J.M. 1988. Techniques for Brucellosis Laboratory. INRA, Paris.

Amenu, K., Thys, E., Regassa, A. and Marcotty, T. 2010. Brucellosis and tuberculosis in Arsi-Negele District, Ethiopia, Prevalence in ruminants and people's behaviour towards zoonoses. J. Trop. 28: 205-210.

Basappa, G. M. and Amarnath, S. K. 2008. Brucellosis in India- A review. Journal of Biosciences 33: 539-547.

Bayasgalan, C., Chultemdorj, T., Roth, F., Zinsstag, J., Hattendorf, J., Badmaa, B. and Schelling, E. 2018. Risk factors of brucellosis seropositivity in Bactrian camels of Mongolia. BMC Veterinary Research, 14(1): 342.

Biancifiori, F., Garrido, F., Nielsen, K., Moscati, L., Durán, M. and Gall, D. 2000. Assessment of a monoclonal antibody based competitive enzyme linked immunosorbent assay (cELISA) for diagnosis of Brucellosis in infected and Rev. 1 vaccinated sheep and goats. New Microbiology 23(4): 399-406.

Blasco, J. M., Marin, C., Jimenez de Bagues, M., Barberan, M., Hernandez, A., Molina, L., Velasco, J., Diaz, R. and Moriyon, I. 1994. Evaluation of allergic and serological tests for diagnosing Brucella melitensis infection in sheep. Journal of Clinical Microbiology 32: 1835-1840.

Boral, R., Singh, M. and Singh, D.K. 2009. Status and strategies for control of Brucellosis. A review. Indian. Journal of Animal Sciences 79: 1191-1199.

CDC 2019. Brucellosis. Centers for Disease Control and Prevention, www.cdc.gov/brucellosis/index.html.

CDC. 2015. Occupational Risks Risk of Exposure Brucellosis. Centers for Disease Control and Prevention. www.cdc.gov/brucellosis/exposure/occ upational-risks.html.

Chauhan, H. C., Patel, K. B., Patel, S. I., Patel, B. K., Chandel B. S., Bhagat, A. G., et al., (2017) Serological survey of brucellosis in camel of Gujarat. International Journal of Current Microbiology and Applied Sciences. 6(4): 1815-1821.

Cloeckaert, A., Debbarh, H. S. A., Vizcanno, N., Saman, E., Dubray, G. and Zygmunt, M.S. 1996a. Cloning, nucleotide sequence, and expression of the Brucella melitensis bp26 gene coding for a protein immunogenic in infected sheep. FEMS Microbiology Letters 140: 139-144.

Cloeckaert, A., Debbarh, H. S. A., Zygmunt, M.S. and Dubray, G. 1996b. Production and characterization of monoclonal antibodies to Brucella melitensis cytosoluble proteins that are able to differentiate antibody responses 
of infected sheep from Rev 1 vaccinated sheep. Journal of Medical Microbiology 45: 206-213.

Corbel, M. 2006. Brucellosis in humans and animals. WHO Press, World Health Organization, Switzerland.

Corbel, M. J. 1972. Characterization of antibodies active in Rose Bengal plate antigen test. Veterinary Record 90: 484-485.

Dawood, H.A. 2008. Brucellosis in camels (Camelus dromedorius) in the south province of Jordan. Journal of Agricultural and Biological Sciences 3(3): 623-626.

Debbarh, H. S. A., Cloeckaert, A., Zygmunt, M.S. and Dubray, G. 1995. Identification of antibodies elicited by infection and Rev 1 vaccination in sheep. Veterinary Microbiology 44: 37-48.

Debbarh, H. S. A., Zygmunt, M., Dubray, G. and Cloeckaert, A. 1996. Competitive enzyme-linked immunosorbent assay using monoclonal antibodies to the $B$. melitensis BP26 protein to evaluate antibody responses in infected and $B$. melitensis Rev 1 vaccinated sheep. Veterinary Microbiology 53: 325-337.

Delgado, S., Fernandez, M. and Carmenes, P. 1995. Evaluation of an enzyme-linked immunosorbent assay for the detection of sheep infected and vaccinated with Brucella melitensis. Journal of Veterinary Diagnostic Investigation 7: 206-209.

Diaz-Aparicio, E., Marin, C, AlonsoUrmeneta, B., Aragon, V., Perez-Ortiz, S., Pardo, M., Blasco, J.M., Diaz, R., and Moriyon, I. 1994. Evaluation of serological tests for diagnosis of Brucella melitensis infection of goats. Journal of Clinical Microbiology 32: 1159-1165.

Espinosa, B. J., Chacaltana, J. and Mulder, M. 2009. Comparison of culture techniques at different stages of brucellosis. Am J Trop Med Hyg. 80: 625.

European Commission. 2001. Scientific committee on Animal Health and Animal Welfare. 107-110. http://ec.europa.eu.

Falade, S. 1978. A comparison of three serological tests in the diagnosis of caprine brucellosis. Research in Veterinary Science 24(3): 376-377.

FAO. 2011. http://www.faostat.fao.org.

FAO. 2019. Dairy Production and Products: Camels. Www.fao.org/dairyproduction-products/production/dairyanimals/camels/en/.

Farah, Z. 1993. Composition and characteristics of camel milk. J. Dairy Res. 60: 603-626. https://doi.org/10.1017/S00220299000 27953

Ferreira, A.C., Cardoso, R., Travassos, D. I., Mariano, I., Belo, A., Rolao, P. I., Manteigas, A., Pina Fonseca, A.M. and Correa De Sa, M.I. 2003. Evaluation of a modified Rose Bengal test and an indirect enzyme-linked immunosorbent assay for the diagnosis of Brucella melitensis infection in sheep. Veterinary Research 34: 297-305.

Ficapal, A., Alonso, B., Velasco, J., Moriyon, I. and Blasco, J. M. 1995. Diagnosis of B. ovis infection of rams with an ELISA using protein $\mathrm{G}$ as conjugate. Veterinary Record 137: 145-147.

Gameel, S.E., Mohamed, S.O., Mustafa, A.A. and Azwai, S.M. 1993. Prevalence of camel brucellosis in Libya. Tropical Animal Health and Production 25: 9193.

Garcell, H. G., Jimenez, R. R., Garcia, E. G., Pueyo, P.V. and Martin, I.R. 2018. Brucellosis related to exposure with camels. J Emerg Rare Dis. 1(2): 108.

Garin-Bastuji, B. and Blasco, J. M. 2004. Caprine and ovine Brucellosis 
(excluding B. ovis). In: Manual of Diagnostic Tests and Vaccines for Terrestrial Animals, $5^{\text {th }}$ ed. OIE, pp. 598-606.

Garin-Bastuji, B., Blasco, J. M., Grayon, M. and Verger, J.M. 1998. Brucella melitensis infection in sheep: present and future. Veterinary Research 29(3/4): 255-274.

Ghoneim, N. A. and Amjad, A. M. 1993. Brucellosis among sheep, goats and camels in Saudi Arabia in Al Joub region: incidence and comparison between Rose Bengal test and seroagglutination tube test. In Proc. $21^{\text {st }}$ Arab Veterinary Medical Congress, 10-14 April, Cairo, 273281.

Godfroid, J., Cloeckaert, A., Liautard, J., Kohler, S., Fretin, D. and Walravens, K. 2005. From the discovery of the Malta fever's agent to the discovery of a marine mammal reservoir, brucellosis has continuously been a reemerging zoonosis. Vet Res. 36: 313326.

Godfroid, J., Saegerman, C., Wellemans, V., Walravens, K., Letesson, J.J., Tibor, A., Mc Millan, A., Spencer, S., Sanna, M., Bakker, D. and Pouillot, R., 2002. How to substantiate eradication of bovine brucellosis when aspecific serological reactions occur in the course of brucellosis testing. Veterinary Microbiology, 90(1-4): 461-477.

Golshani, M. and Buozari, S. 2017. A review of Brucellosis in Iran: epidemiology, risk factors, diagnosis, control, and prevention. Iran. Biomed. J. 21: 349.

Graber, M. 1968. Central African Region of Veterinary and Zootechnical Research. Annual Report of the Farcha Laboratory, Fort Lamy, Chad. I. Research and Products. Vet. Bull., 38: 52-65.
Greenfield, R. A., Drevets, D. A., Machado, L. J., Voskuhl, G. W., Cornea, P. and Bronze, M.S. 2002. Bacterial pathogens as biological weapons and agents of bioterrorism. Am J Med Sci. 323: 299-315.

Grunow, R., Jacob, D., Klee, S., Schlembach, D., Jackowski-Dohrmann, S., Loenning-Baucke, V., Eberspächer, B. and Swidsinski, S. 2016. Brucellosis in a refugee who migrated from Syria to Germany and lessons learnt, 2016. Euro Surveill. 21(31): 311.

Gul, S.T., Khan, A., Rizvi, F. and Hussain, I. 2014. Sero-prevalence of brucellosis in food animals in the Punjab, Pakistan. Pak Vet J. 34(4): 454-458.

Gwida, M., El-Gohary, A. H., Melzer, F., Tomaso, H., Rösler, U., Wernery, U., Wernery, R., Elschner, M. C., Khan, I. and Eickhoff, M. 2011. Comparison of diagnostic tests for the detection of Brucella spp. in camel sera. BMC Research Notes 4(1): 1-7.

Gwida, M., El-Gohary, A., Melzer, F., Khan, I., Rösler, U. and Neubauer, H. 2012. Brucellosis in camels. Res Vet Sci. 92(3): 351-355.

Habtamu, T.T., Richard, B., Dana, H. and Kassaw, A. T. 2015. Camel Brucellosis: Its public health and economic impact in pastoralists, Mehoni District, Southeastern Tigray, Ethiopia Journal of Microbiology Research 5(5): 149-156. DOI: 10.5923/j.microbiology.20150505.02.

Hadush, A., Pal, M., Kassa, T. and Zeru, F. 2013. Sero-epidemiology of camel brucellosis in the Afar region of Northeast Ethiopia. Acad. J. 5: 269275.

https://doi.org/10.5897/JVMAH13.023 5.

Jiménez de Bagüés, M. P., Marin, C. M. and Blasco, J. M. 1992. An ELISA with Brucella lipopolysaccharide antigen 
for the diagnosis of $B$. melitensis infection in sheep and for the evaluation of serological responses following subcutaneous or conjunctival B. melitensis strain rev. 1 vaccination. Veterinary Microbiology 30: 233-241.

Kadim, I. T., Mahgoub, O. and Purchas, R. W. 2008. A review of the growth, and of the carcass and meat quality characteristics of the one-humped camel (Camelus dromedarius). Meat Sci.80: 555-569.

Kadle, A. A. H., Mohamed, S. A., Ibrahim, A. M. and Alawad, M. F. 2017. Seroepidemiological study on camel Brucellosis in Somalia. European Academic Research 5(6): 2925-2942.

Kadri, S. M., Rukhsana, A., Lahqrwal, M. A. and Tanvir, M. 2000. Sero-prevalence of brucellosis in Kashmir (India) among patients with pyrexia of unknown origin. J. Ind. Med. Asso. 90(4): 170-171.

Kalla, A., Chadda V. S. L., Gauri, A., Gupta, A., Jain, S., Gupta, B. K., Chaddha, S., Nayak, K. C., Singh, V. B. and Kumhar, M. R. 2001. Out break of polyarthritis with pyrexia in Western Rajasthan. J Assoc Physicians India 49: 963 - 965.

Khadjeh, G., Zowghi, E. and Zarif-Fard, M. 1999. Incidence of brucellosis in onehumped camels of Boushehr, Iran. Archives of Razi Institute 50: 83-86.

Khaskheli, M., Arain, M., Chaudhry, S., Soomro, A. and Qureshi, T. 2005. Physico-chemical quality of camel milk. J. Agric. Soc. Sci. 2: 164-166.

Kochar, D. K., Gupta, B. K., Gupta, A., Kalla, A., Nayak, K. C. and Purohit, S. K. 2007. Hospital based case series of 175 cases of serologically confirmed Brucellosis in Bikaner. J Assoc Physicians India.55: 271-275. http://japi.org/april2007/O-271.htm.
Kumar, A. and Nanu, E. 2005. Seropositive of Brucellosis in Human beings. Ind. J. Pub. Health. 49(1): 22-24.

LPPS. 2005. Saving the camel and peoples' livelihoods: Building a multistakeholder platform for the conservation of the camel in Rajasthan. Proceedings of International Conference on Camel. Sadri. Lokhit Pashu-Palak Sansthan, 23-25 November 2004 Sadri, Rajasthan, India.

MacMillan, A. 1990. Conventional serological tests. In Nielsen $\mathrm{K}$ and Duncan J.R. (Eds.), Animal Brucellosis, CRC Press, Boca Raton, Florida pp 153-197.

Mantur, G. and Amarnath, K. 2008. Brucellosis in India, a review. J. Biosci. 33: 539 - 547.

Marín, C. M., Moreno, E., Moriyón, I., Díaz, R. and Blasco, J. M. 1999. Performance of competitive and indirect enzyme-linked immunosorbent assays, gel immunoprecipitation with native hapten polysaccharide, and standard serological tests in diagnosis of sheep brucellosis. Clinical Diagnostic and Laboratory Immunology 6(2): 269-272.

Mathur K. N. and Bhargava, S. C. 1979. Seroprevalence of $\mathrm{Q}$ fever and brucellosis in camels of Jorbeer and Bikaner, Rajasthan State. Indian J. Med. Res., 70 (11): 391-393.

Mathur, T.N. 1964. Brucella strains isolated from cows, buffaloes, goats, sheep and human beings at Karnal: Their significance with regard to the epidemiology of brucellosis. Ind. Jour. Med. Res. 52: 1231-1230.

Mekonnen, K. 2016. Study on camel and human Brucellosis in Fentale District, East Shoa Zone, Oromia Regional State, Ethiopia. Journal of Biology, Agriculture and Healthcare. 6 (15): 117. 
Mirmiran, P., Ejtahed, H. S., Angoorani, P., Eslami, F., and Azizi, F. 2017. Camel milk has beneficial effects on Diabetes Mellitus: A systematic review. International Journal of Endocrinology and Metabolism, 15(2): e42150. doi:10.5812/ijem.42150.

Musa, M. T. and Shigidi, M. T. A. 2001. Brucellosis in camels in intensive animal breeding areas of Sudan. Implications in abortion and early-life infections. Reviews in Science and Technology 54: 11-15.

Musa, M. T., Eisa, M. Z., El Sanousi, E. M., Abdel Wahab, M.B. and Perrett, L. 2008. Brucellosis in camels (Camelus dromedarius) in Darfur, Western Sudan. Journal of Comparative Pathology 138: 151-155.

Neha, A., Kumar, A. and Ahmed, I. 2017. Comparative efficacy of serological diagnostic methods and evaluation of polymerase chain reaction for diagnosis of bovine brucellosis. Iran. J. Vet. Res. 18: 279.

Nielsen, K., Cherwonogrodsky, J., Duncan, R. and Bundle, D. 1989. Enzyme immunoassay for the differentiation of antibody response of Brucella abortus infected and vaccinated cattle. American Journal of Veterinary Research 50: 5-9.

Nielsen, K., Smith, P., Gall, D., Perez, B., Samartino, L., Nicoletti, P., Dajer, A., Rojas, X. and Kelly, W., 2001. Validation of the fluorescence polarization assay for detection of milk antibody to Brucella abortus. Journal of Immunoassay and Immunochemistry 22(3): 203-211.

Nimri, L.F. 2003. Diagnosis of recent and relapsed cases of human brucellosis by PCR assay. BMC Infect Dis. 3: 5.

OIE. 2008. Bovine brucellosis. In Manual of Diagnostic Tests and Vaccines. OIE, Paris pp 624- 659.
OIE. 2009. Manual of Diagnostic Tests and Vaccines for Terrestrial Animals. World Organisation for Animal Health, Paris, France.

Omer, A. K., Bahbil, A. E. A., Hassan, N. A. and El-Wahab A. M. A. 2010a. Pathophysiological investigations on brucellosis in she-camels. Global Veterinaria 4 (5): 495-503.

Omer, M. M., Musa, M. T., Bakhiet, M. R. and Perrett, L. 2010b. Brucellosis in camels, cattle, and humans: associations and evaluation of serological tests used for diagnosis of the disease in certain nomadic localities in Sudan. Rev Sci Tech. 29: 663-669.

Pal'gov, A. A. and Zhulobovski, I. Z. 1964. Diagnosis of brucellosis in camels and methods of eliminating infection from camel herds. Trudy Inst. Vet. Akademiya Nauk, Kazakhskoi SSR, Alma Ata 6: 43-50.

Pandit, D. P. and Pandit, P. T. 2013. Human brucellosis: are we neglecting an enemy at the backyard? Med J Dr D Y Patil Uni. 6: 350-358. DOI 10.4103/0975-2870.118265.

Pappas, G., Papadimitriou, P., Akritidis, N., Christou, L. and Tsianos, V. 2006. The new global map of human brucellosis. Lancet Infect, 6: 91-99.

Phadke, S. A. and Phadke, A. R. 1974. Prevalence of Brucella agglutinins in sera received for serological test for Syphilis and Widal test. Ind. Jour. Med. Sci. 8(4): 323-326.

Radostits, W., Gay, C.C., Hinchcliff, K.W. and Constable, P.D. 2007. Veterinary Medicine, $10^{\text {th }}$ edn. Elsevier Saunders, London, pp 389-390.

Radwan, A.I., Bekair, S.I. and Prasad, P.V.S. 1992. Serological and bacteriological study of brucellosis in camels in central Saudi Arabia. Revue Scientifique et Technique Office 
Internationale des Epizootes 11(3): 837-844.

Radwan, A. I., Bekairi, S. I., Mukayel, A. A., Al-Bokmy, A. M., Prasad, P. V., Azar, F. N. and Coloyan, E. R. 1995. Control of Brucella melitensis infection in a large camel herd in Saudi Arabia using antibiotherapy and vaccination with Rev. 1 vaccine. Revue Scientifique et Technique (International Office of Epizootics) 14(3): 719-732.

Ramet, J.P. 2001. The technology of making cheese from camel milk. FAO. Animal Production and Health Papers. 17-20.

Ramirez-Romero, R. 1998. Is Brucella abortus a facultative intracellular pathogen with mitochondria-like activity? Medical Hypotheses 51: 4145.

Reddy, R. R., Prejit, S. B.,Vinod, V. K. and Asha, K. 2014. Seroprevalence of brucellosis in slaughter cattle of Kerala, India. Journal of Food borne and Zoonotic Diseases 2(2): 27-29.

Renukaradhya, G. J., Isloor, S. and Rajasekhar, M. 2002. Epidemiology, zoonotic aspects, vaccination and control/eradication of brucellosis in India. Veterinary Microbiology 90: 183-95.

Richard, D. 1980. Dromedary pathology and productions. Paper presented at a workshop on camels, 18-20 December, Khartoum, Sudan. Provisional Report No. 6. Camels. International Foundation for Science, Stockholm, pp 409-430.

Rossetti, O. L., Arese, A. I., Boschiroli, M. L. and Cravero, S. L. 1996. Cloning of Brucella abortus gene and characterization of expressed 26kilodalton periplasmic protein: potential use for diagnosis. Journal of Clinical Microbiology 34: 165-169.

Roushan, M. R., Amin, M. J., Abdoel, T. H. and Smits, H. L. 2005. Application of a user-friendly Brucella-specific IgM and $\mathrm{IgG}$ antibody assay for the rapid confirmation of Rose Bengal-positive patients in a hospital in Iran. Trans. R. Soc. Trop. Med. Hyg. 99:.744-750.

Sathyanarayanan, V., Razak, A., Saravu, K., Ananthakrishna, S. B., Mukhyprana, P. M. and Vandana, K. E. 2011. Clinical profile of brucellosis from a tertiary care center in southern India. Asian Pac. J. Trop. Med. 1: 397-400.

Schelling, E., Diguimbaye, C., Nicolet, J., Boerlin, P., Tanner, M. and Zinsstag, J. 2003. Brucellosis and Q-fever seroprevalences of nomadic pastoralists and their livestock in Chad. Prev. Vet. Med. 61: 279-293.

Schwartz, H. J. and Dioli, M. 1992. The onehumped camel in Eastern-Africa Weikersheim: Editions Verlag p 282.

Shahzad, A., Khan A., Khan M. Z. and Saqib, M. 2017. Seroprevalence and molecular investigation of brucellosis in camels of selected districts of Punjab, Pakistan. Thai J. Vet. Med. 47(2): 207-215.

Shimol, S. B., Dukhan, L., Belmaker, I., Bardenstein, S., Sibirsky, D., Barrett, C., Greenberg, D. 2012. Human brucellosis outbreak acquired through camel milk ingestion in southern Israel. Isr. Med. Assoc J. 14(8): 475478 .

Shome, R., Gupta, V. K., Bhardwaj, B. Shome, B., Mohandoss, N. and Rahman, H. 2013. A report of seroprevalence of camel brucellosis in India. Journal of Camel Practice and Research. 20: 183-186.

Sprague, L. D., Al-Dahouk, S., and Neubauer, H. 2012. A review on camel brucellosis: a zoonosis sustained by ignorance and indifference. Pathogens and Global Health 106: 144-149. doi: 10.1179/2047773212Y.0000000020.

Thakur, S. D. and Thapliyal, D. C. 2002. 
Seroprevalence of brucellosis in Man. J. Commu. Dis. 34(2): 106-109.

Verma, S. 2018. Camel Milk Is Gaining Popularity. Could It Be an Alternative for Dairy Market? The Financial Express November 11, 2018. www.financialexpress.com/industry/ca mel-milk-is-gaining-popularity-couldit-be-an-alternative-for-dairymarket/1378177/.

Wakene, W. Z. and Mamo, G. 2017. Review on epidemiology of camel and human Brucellosis in East Africa, IGAD Member Countries. International Journal of Communication Sciences and Disorders. 1(2):51-57 http://www.sciencepublishinggroup.co $\mathrm{m} / \mathrm{j} / \mathrm{ijcsd}$.

WHO 2006. Brucellosis in humans and animals, WHO/CDS/EPR 7: 1-89. http://www.who.int/csr/resources/ publications/Brucellosis.pdf.

Wilson, D. E. and Reeder, D. M. 2005.
Mammal species of the world. Baltimore, MD: Johns Hopkins University Press.

Zewolda, S. W. and Wereta, M. H. 2012. Seroprevalence of Brucella infection in camel and its public health significance in selected districts of Afar region, Ethiopia. Journal of Environmental and Occupational Health, 1(2): 91-98. doi: 10.5455/jeos.20120711034013.

Zibaee, S., Hosseini, S. M., Yousefi, M., Taghipour, A., Kiani, M. A. and Noras, M. R. 2015. Nutritional and therapeutic characteristics of camel milk in children: a systematic review. Electronic physician, 7(7): 1523-1528. doi:10.19082/1523.

Zowghi, E., Ebadi, A. and Yarahmadi, M. 2008. Isolation and identification of Brucella organisms in Iran. Iranian Journal of Clinical Infectious Diseases 3(4): $185-188$.

\section{How to cite this article:}

Neharika Saxena and Rajni Joshi. 2021. Brucellosis in Camels and its Public Health Significance for Humans. Int.J.Curr.Microbiol.App.Sci. 10(04): 445-462. doi: https://doi.org/10.20546/ijcmas.2021.1004.047 